\title{
Cyclin D1 expression in KRAS mutant non-small cell lung cancer-old wine into new skins
}

\author{
Kah Yee Goh ${ }^{1}$, Wan-Teck Lim ${ }^{1,2,3}$ \\ ${ }^{1}$ Division of Medical Oncology, National Cancer Centre Singapore, Singapore; ${ }^{2}$ Office of Academic and Clinical Development, Duke-NUS Medical \\ School, Singapore; ${ }^{3}$ Institute of Molecular and Cell Biology, A*Star, Proteos, Singapore \\ Correspondence to: Wan-Teck Lim. Division of Medical Oncology, National Cancer Centre Singapore, 11 Hospital Drive, Singapore. \\ Email: darren.lim.w.t@singhealth.com.sg. \\ Comment on: Luangdilok S, Wanchaijiraboon P, Chantranuwatana P, et al. Cyclin D1 expression as a potential prognostic factor in advanced KRAS- \\ mutant non-small cell lung cancer. Transl Lung Cancer Res 2019;8:959-66.
}

Submitted May 08, 2020. Accepted for publication May 18, 2020.

doi: $10.21037 /$ tlcr-20-639

View this article at: http://dx.doi.org/10.21037/tlcr-20-639

Globally, lung cancer has the highest mortality rate among all cancers $(1,2)$. Non-small cell lung cancer (NSCLC) comprises $>80 \%$ of cases (3). Oncogene driver mutations in EGFR, MET, KRAS, ALK, BRAF are commonly described in NSCLC (4). The prevalence of KRAS mutation is higher in Western population ( $30 \%)$ compared to Asian population $(\sim 10 \%)(4,5)$. This is attributed to the varying prevalence of smoking in the different populations and early role of KRAS in carcinogenesis among smokers (6). KRAS encodes a cytoplasmic GTPase that shuttles between the active GTPbound form and the inactive GDP-bound form, regulated by GEFs and GAPs. In the active form, KRAS transduces signal from cell surface receptors to downstream effectors, regulating key cellular processes such as proliferation and survival (7). In KRAS mutant NSCLC, activating missense mutations involving codons 12, 13 and 61 lock the KRAS GTPase in a constitutive active form, initiating downstream signaling and promoting uncontrolled cell proliferation and survival in the absence of ligand stimulation. A downstream effector of KRAS is Cyclin D1/CCND1, which controls cell division by regulating CDK4/6 activity during G1-S transition of the cell cycle. Cyclin D1 is frequently upregulated in many cancer types (8). In NSCLC, CCND1 gene amplification was observed in up to $32 \%$ of cases but cyclin D1 overexpression was found in up to $76 \%$ of cases (9), indicating additional signaling mechanisms exist to induce cyclin D1 overexpression but these mechanisms are not fully elucidated yet.

Despite being an oncogenic driver, targeted therapies against KRAS have been slow in development due to the lack of suitable "pockets" for small molecule binding (4). However, KRAS G12C mutant-specific small molecule inhibitors such as AMG510, MRTX849, JNJ-74699157 (10-12) have gained traction in the last year and an inhibitor of the SOS1:KRAS protein-protein interaction, BI3406, with wide KRAS inhibitory activity have been reported (13). Nevertheless, treatment strategies for KRAS mutant NSCLC remain limited and chemotherapy remains as the standard of care (4). As such, prognosis for NSCLC remains poor especially in patients with advanced disease (14). Numerous clinical studies have investigated the prognostic value of KRAS mutations in NSCLC but the results were variable due to differences in patient populations and endpoints (15). Therefore, there is a need for new prognostic markers in KRAS mutant NSCLC patients to improve disease control and selection of the best treatment strategy.

In an effort to identify potential prognostic markers in KRAS mutant NSCLC, Luangdilok et al. (in 2019) evaluated the expression of cyclin D1 protein on the overall survival in a Thai population of NSCLC patients with mutant KRAS versus wild type KRAS (16). The authors enrolled 95 NSCLC patients with wild type EGFR and studied the clinical characteristics, prevalence of the KRAS mutation and expression of cyclin D1. Most patients were in the advanced stage IV $(73.7 \%)$ of the disease and most cases were adenocarcinoma (90.5\%). 28 of them $(29.5 \%)$ carried KRAS mutation while the remaining 67 (70.5\%) were wild 
type for $K R A S$. Among the clinical characteristics, not surprisingly, smoking history $(\mathrm{P}=0.001)$ and male gender $(\mathrm{P}<0.001)$ associated significantly with the presence of the KRAS mutation. Furthermore, NSCLC patients with KRAS mutation $(\mathrm{n}=28)$ had significantly shorter overall survival compared to patients with wild type KRAS (n=67) (median survival of 5.2 vs. 13.2 months). Interestingly, the authors demonstrated that NSCLC tumors with KRAS mutation $(\mathrm{n}=24)$ had a significantly higher expression of cyclin D1 protein than NSCLC tumors with wild type KRAS ( $\mathrm{n}=36)$.

Luangdilok et al. (in 2019) go on to suggest that mutant KRAS protein may induce cyclin D1 overexpression through constitutive activation of the RAS-MEK-ERK pathway. Within the group of NSCLC patients with KRAS mutation, those with high cyclin D1 expression $(n=14)$ had markedly shorter overall survival compared to those with low cyclin D1 expression $(\mathrm{n}=4)$ (median survival of 3.5 vs. 41.7 months). The association of poor prognosis with CCND1 overexpression and KRAS mutation status has been similarly suggested in early stage NSCLC by Dragoj et al. (in 2015) in a previous paper (17). In addition, Halilovic et al. (in 2010) suggested in KRAS mutant cancer cell lines that cyclin D1 expression was dependent on PIK3CA mutations and MEK/ERK inhibition as well (18). Hence, the definitive mechanistic links in KRAS mutant NSCLC have not been fully established, and future work will need to address if co-targeting KRAS mutant protein, and others such as PIK3CA and MEK/ERK will be potentially synergistic and beneficial for this disease. Studies using candidate gene approaches with small sample sizes as adopted by Luangdilok et al. (in 2019) remain hypothesisgenerating. The roles of other genes such as PIK3CA in the regulation of cyclin D1 expression were not studied. The sample size is small and thus the findings may not be representative in a larger dataset. Future studies should be performed in larger cohorts and incorporate coexistent PIK3CA mutations and MEK/ERK pathway activation in the analysis to validate the prognostic role of cyclin D1 in KRAS mutant NSCLC.

Recently, the field of study into KRAS mutant NSCLC has taken on new directions, and there is renewed interest in this previously "undruggable" target. This study among others should provide further impetus to develop "new" understanding and treatments for this "old" target.

\section{Acknowledgments}

Funding: We thank the funding support provided by
National Medical Research Council (NMRC/CSAINV/0025/2017).

\section{Footnote}

Provenance and Peer Review: This article was commissioned by the editorial office, Translational Lung Cancer Research. The article did not undergo external peer review.

Conflicts of Interest: Both authors have completed the ICMJE uniform disclosure form (available at http://dx.doi. org/10.21037/tlcr-20-639). The authors have no conflicts of interest to declare.

Etbical Statement: The authors are accountable for all aspects of the work in ensuring that questions related to the accuracy or integrity of any part of the work are appropriately investigated and resolved.

Open Access Statement: This is an Open Access article distributed in accordance with the Creative Commons Attribution-NonCommercial-NoDerivs 4.0 International License (CC BY-NC-ND 4.0), which permits the noncommercial replication and distribution of the article with the strict proviso that no changes or edits are made and the original work is properly cited (including links to both the formal publication through the relevant DOI and the license). See: https://creativecommons.org/licenses/by-nc-nd/4.0/.

\section{References}

1. Siegel RL, Miller KD, Jemal A. Cancer statistics, 2019. CA Cancer J Clin 2019;69:7-34.

2. Torre LA, Siegel RL, Jemal A. Lung Cancer Statistics. Adv Exp Med Biol 2016;893:1-19.

3. Roman M, Baraibar I, Lopez I, et al. KRAS oncogene in non-small cell lung cancer: clinical perspectives on the treatment of an old target. Mol Cancer 2018;17:33.

4. Yang H, Liang SQ, Schmid RA, et al. New Horizons in KRAS-Mutant Lung Cancer: Dawn After Darkness. Front Oncol 2019;9:953.

5. Dearden S, Stevens J, Wu YL, et al. Mutation incidence and coincidence in non small-cell lung cancer: metaanalyses by ethnicity and histology (mutMap). Ann Oncol 2013;24:2371-6.

6. Thunnissen FB, Prinsen C, Hol B, et al. Smoking history and lung carcinoma: KRAS mutation is an early hit in lung adenocarcinoma development. Lung Cancer 
2012;75:156-60.

7. Karnoub AE, Weinberg RA. Ras oncogenes: split personalities. Nat Rev Mol Cell Biol 2008;9:517-31.

8. Musgrove EA, Caldon CE, Barraclough J, et al. Cyclin $\mathrm{D}$ as a therapeutic target in cancer. Nat Rev Cancer 2011;11:558-72.

9. Gautschi O, Ratschiller D, Gugger M, et al. Cyclin D1 in non-small cell lung cancer: a key driver of malignant transformation. Lung Cancer 2007;55:1-14.

10. Fakih M, O'Neil B, Price TJ, et al. Phase 1 study evaluating the safety, tolerability, pharmacokinetics (PK), and efficacy of AMG 510, a novel small molecule KRASG12C inhibitor, in advanced solid tumors. J Clin Oncol 2019;37:3003.

11. Hallin J, Engstrom LD, Hargis L, et al. The KRAS(G12C) Inhibitor MRTX849 Provides Insight toward Therapeutic Susceptibility of KRAS-Mutant Cancers in Mouse Models and Patients. Cancer Discov 2020;10:54-71.

12. Mullard A. Cracking KRAS. Nat Rev Drug Discov 2019;18:887-91.

13. Hofmann MH, Gmachl M, Ramharter J, et al. Discovery of BI-3406: A potent and selective SOS1: KRAS inhibitor

Cite this article as: Goh KY, Lim WT. Cyclin D1 expression in KRAS mutant non-small cell lung cancer-old wine into new skins. Transl Lung Cancer Res 2020;9(6):2302-2304. doi: 10.21037/tlcr-20-639 opens a new approach for treating KRAS-driven tumors. Molecular Cancer Therapeutics 2019;18:Abstract PL06-01.

14. Zappa C, Mousa SA. Non-small cell lung cancer: current treatment and future advances. Transl Lung Cancer Res 2016;5:288-300.

15. Martin P, Leighl NB, Tsao MS, et al. KRAS mutations as prognostic and predictive markers in non-small cell lung cancer. J Thorac Oncol 2013;8:530-42.

16. Luangdilok $S$, Wanchaijiraboon $P$, Chantranuwatana $P$, et al. Cyclin D1 expression as a potential prognostic factor in advanced KRAS-mutant non-small cell lung cancer. Transl Lung Cancer Res 2019;8:959-66.

17. Dragoj M, Milosevic Z, Bankovic J, et al. Association of CCND1 overexpression with KRAS and PTEN alterations in specific subtypes of non-small cell lung carcinoma and its influence on patients' outcome. Tumour Biol 2015;36:8773-80.

18. Halilovic E, She QB, Ye Q, et al. PIK3CA mutation uncouples tumor growth and cyclin D1 regulation from MEK/ERK and mutant KRAS signaling. Cancer Res 2010;70:6804-14. 